\title{
Cervicogenic headache arising from hidden metastasis to cervical lymph node adjacent to the superficial cervical plexus -A case report-
}

\author{
Hwan Hee Kim, Yong Chul Kim, Yong Hee Park, Jin Woo Park, Jae-Hun Kim, Soo-Young Park, and \\ Sang Chul Lee
}

Department of Anesthesiology and Pain Medicine, Seoul National University College of Medicine, Seoul, Korea

The differential diagnosis of headache is often difficult because the symptom of headache is overlapping. Superficial cervical plexus block is useful in diagnosis and treatment of headache. Headache arising from the neck and radiating to the frontotemporal regions and possibly to the supraorbital region has been defined as cervicogenic headache. A positive response to anesthetic blocks is one of the diagnostic criteria of cervicogenic headache. We experienced a case of headache arising from direct lymph node metastasis of hepatocellular carcinoma adjacent to the superficial cervical plexus during treatment of cervicogenic headache under ultrasonographic guidance. Especially in patients with medical history of cancer, practitioners should consider the possibility of metastasis to cervical lymph nodes and using ultrasonography to evaluate the cervical area prior to the practice. (Korean J Anesthesiol 2011; 60: 134-137)

Key Words: Cervicogenic headache, Diagnostic block, Metastasis, Superficial cervical plexus, Ultrasonography.

Confronting patients with headache, it is often difficult to determine its etiology. Even though most headaches have a benign course, it is important to differentiate primary from secondary headache because the latter might be caused by neoplasm.

Cervicogenic headache is a secondary form of headache mainly characterized by pain unilaterally referred to the fronto-temporal or possibly the supraorbital area [1]. Most cervicogenic headaches are derived from the cervical facet joint, posterior neck muscles, greater or third occipital nerve. However, the superficial cervical plexus can also cause localized neuropathic pain around the ear via the lesser occipital nerve and auricular nerves [2].

In cases where the superficial cervical plexus is suspected of causing headache on history and physical examinations, a diagnostic block can be performed between the sternocleidomastoid muscle and the levator scapulae muscle [2]. Although a superficial cervical plexus block can be performed

Received: June 30, 2010. Revised: 1st, August 9, 2010; 2nd, September 3, 2010. Accepted: October 6, 2010.

Corresponding author: Yong Chul Kim, M.D., Ph.D., Department of Anesthesiology and Pain Medicine, Seoul National University College of Medicine, 101, Daehang-no, Jongno-gu, Seoul 110-744, Korea. Tel: 82-2-2072-2469, Fax: 82-2-747-5639, E-mail: pain@snu.ac.kr

This Article Presented at the 50th Scientific Meetings of the Korean Pain Society, May, 2010.

(c) This is an open-access article distributed under the terms of the Creative Commons Attribution Non-Commercial License (http:// creativecommons.org/licenses/by-nc/3.0/), which permits unrestricted non-commercial use, distribution, and reproduction in any medium, provided the original work is properly cited. 
using a blind technique, ultrasonographic scanning is thought to be essential before needle insertion, especially in patients with medical history of cancer.

Herein, we report the management of headache derived from hidden metastasis to a cervical lymph node adjacent to the superficial cervical plexus under ultrasonographic guidance.

\section{Case Report}

A 65-year-old male was referred to our pain center for management of a severe headache lasting 4 months. His pain was located in the left auriculotemporal area, and its intensity was 8 out of 10 on the $10 \mathrm{~cm}$-visual analogue scale (VAS).

On medical history, he had received one percutaneous ethanol injection and nine transarterial chemo embolizations for hepatocelluar carcinomas caused by hepatitis B virus infection. Four months before referral to us, a gamma-knife surgery was performed successfully for suspicious metastatic brain lesions in the left frontal lobe and bilateral cerebellar hemisphere, which were found on MRI. However, his headache did not subside.

At first, it was suspected that the cause of headache was an intracranial mass, but there was no sign of increased intracranial pressure. His headache, however, was continuously non-throbbing with a radiating pattern without morning exacerbation. Since the area of headache was corresponding to the dermatomes of the greater auricular nerve and lesser occipital nerves, a superficial cervical plexus block was planned as a diagnostic trial with $2 \mathrm{ml}$ of $0.125 \%$ levobupivacaine (Chirocaine $^{\circledR}$, Abbott, Elverum, Norway) under ultrasonographic guidance.

After obtaining informed consent from the patient and his family, he was placed in the right lateral decubitus position and draped in sterile fashion.

Despite no prominent palpable mass on physical examination

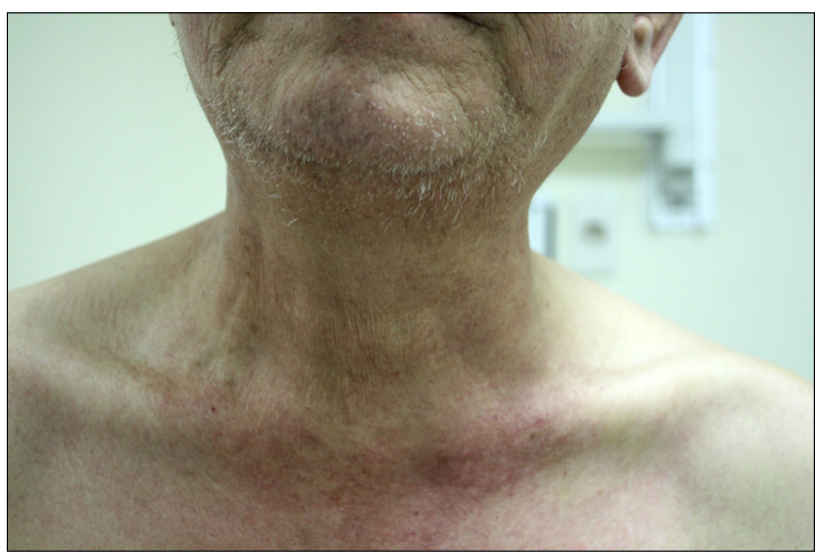

Fig. 1. There was no palpable mass on the patient's neck.
(Fig. 1), we found a spherical shaped mass, which was approximately $2 \times 2 \mathrm{~cm}$ at his left anterior neck on pre-scan of ultrasonography (S-Nerve ${ }^{\circledR}$, SonoSite, Bothell, WA with 10-MHz high frequency linear probe) (Fig. 2).

Hence, after changing the patient position from right lateral decubitus to supine with his neck rotated to contralateral side, the superficial cervical plexus block was performed. In order to avoid the possibility of phrenic nerve block, the mass located at the thickened side of interfascial layer of sternocleidomastoid muscle at the $\mathrm{C} 6$ level was avoided. The patient experienced

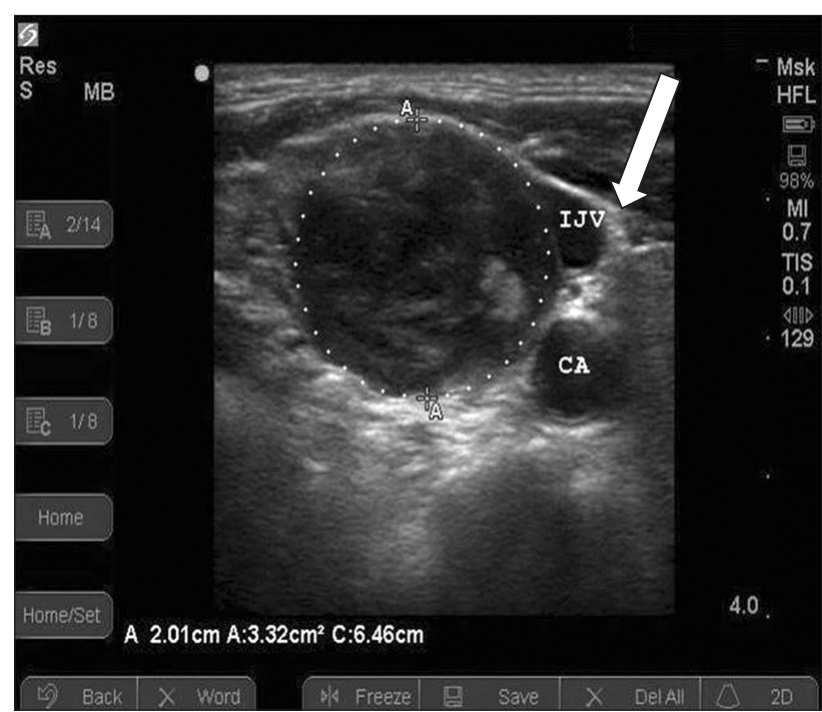

Fig. 2. US image shows $2 \mathrm{~cm}$ sized hypoechoic enlargement of cervical lymph node adjacent to superficial cervical plexus. The tip of needle was positioned in the thickend interfascial plane of sternocleidomastoid muscle as arrow directed in the figure.

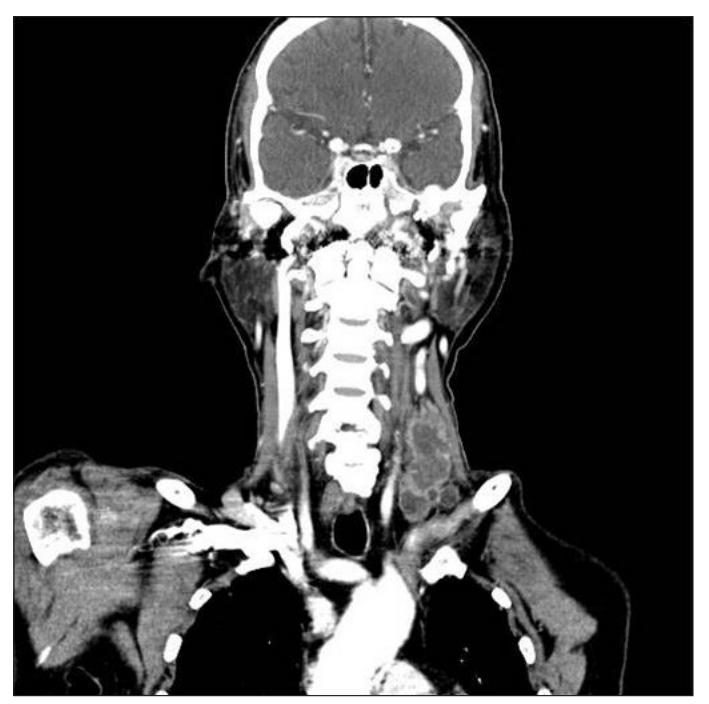

Fig. 3. Neck CT image shows metastatic lesion to lymph node adjacent to superficial cervical plexus. 
immediate relief of the headache on completion of injection.

Since the ultrasonographic scan of the mass showed mixed echogenicity, a metastatic legion was suspected. On followup neck computed tomography scan (Fig. 3), multiple metastases to lymph nodes were found, which corresponded to ultrasonographic findings.

After 1 week from the first attempt of superficial cervical plexus block, the patient complained his headache had recurred, so a second block was performed with local anesthetics and 20 mg of triamcinolone acetonide (Hanall, Seoul, Korea). The headache disappeared again and the patient was transferred to the department of oncology for managing metastatic lesions with medications for neuropathic pain.

\section{Discussion}

Headache is one of the most common symptoms with a $100 \%$ life time prevalence. However, its course is most often benign and rarely life-threatening. Headache is classified into primary and secondary headache. Primary headache is classified into migraine, cluster headache, and tension-type headache, and secondary headache is classified into vascular, neoplastic, infectious, metabolic, and toxic disorders [1]. However, it is difficult to differentiate secondary from primary headache, and often people mistake secondary headache for primary headache based on incidence. However, there is no specific diagnostic tool and it is diagnosed mainly on patient medical history, physical examination and diagnostic block.

Superficial cervical plexus block is a useful modality for postauricular and temporal area headache mediated greater auricular nerve and lesser occipital nerve. Superficial cervical plexus supplies innervations to the skin of the anterolateral neck through anterior primary rami of C2 through C4 $[2,3]$. Four distinct nerves emerge from the posterior border of the sternocleidomastoid muscle, the lesser occipital, greater auricular, transverse cervical and supraclavicular nerves [4]. Therefore, superficial cervical plexus block is used for diagnosis and treatment of headache, including. headache after carotid endartectomy and neck surgery $[5,6]$.

Cervicogenic headache originates in the neck, limits neck range of motion, and can be prolonged and fluctuating. The character of pain is usually non-throbbing with moderate intensity. Cervicogenic headache arises from the neck and radiates to the fronto-temporal and possibly the supraorbital region [2]. A history of long lasting, strictly unilateral headache is suggestive of cervicogenic headache, especially the temporal area headache. In addition, its non-throbbing nature and chronic fluctuating pattern distinguish cervicogenic headache from other unilateral headaches. Cervicogenic headache has been defined as a unilateral headache without side-shift but it can occur bilaterally. In such cases, positive response to an appropriate anesthetic block might be essential in clinical practice [7].

Cervicogenic headache is not diagnostic terminology but a description of the patient's symptom. There is no specific finding for it on any imaging study or standard examination, and the diagnosis is based on medical history, pain characteristics and physical examinations. Medication, physical treatment, biofeedback, and relaxation are usually used to treat cervicogenic headache, but their efficacy is unproven. Other invasive treatments include trigger point injection, stellate ganglion block, and second cervical ganglion block following radiofrequency coagulotherapy [8].

There are few data predictive efficacy of pheripheral nerve blocks, and there are currently no data as to the optimal dose, volume, or type of local anesthetic to be used for nerve blocks or trigger point injections in headache management. However, interventional procedures, such as nerve blocks and trigger point injections, have long been used in the treatment of various headache disorders [9-11].

Our patient kept taking treatment from the oncologic and neurologic departments, and the brain metastasis was treated by gamma knife four month ago. Therefore, we could rule out brain metastasis as the cause of headache. In addition, the headache was located in the temporal area with radiating pain, which is suggestive off cervicogenic headache. Ultrasonography-guided superficial cervical plexus block was then performed for diagnosis and treatment. Under ultrasonographic view, the hypertrophic supraclavicular lymph node was detected. Further work up was done after transfer to the internal medicine department, and the lymph node was revealed to be a metastasis of hepatocellular carcinoma in neck CT.

Since the metastatic lymph node was not palpable around the patient's neck during the physical examination, the headache was initially managed without regarding the chance of cancer metastasis.

According to the subsidence of pain scale after the trial of superficial cervical plexus block, the patient's cervicogenic headache was considered to be caused by direct lymph node metastasis.

This case shows that metastatic lesion involving anatomical structures of the neck region causes headache in a similar manner to cervicogenic headache. This case also shows that soft tissue problems in the neck region may also cause headache or headache-like pain.

Clinicians who care for patients with malignancy suffering from headache need to consider the possibility of pain from cervical metastatic lesions and should include the test to evaluate the cervical lesion besides brain. A careful 
ultrasonographic pre-scan is thought to be essential before nerve block injection, especially in patients with medical history of cancer.

Furthermore, palliative management of unexplained symptoms for cancer patient requires a multidisciplinary approach performed by a well-trained neuro-oncology team.

\section{References}

1. Ashkenazi A, Silberstein SD. Headache management for the pain specialist. Reg Anesth Pain Med 2004; 29: 462-75.

2. van Suijlekom H, Van Zundert J, Narouze S, van Kleef M, Mekhail N. 6. Cervicogenic headache. Pain Pract 2010; 10: 124-30.

3. Yi X, Cook AJ, Hamill-Ruth RJ, Rowlingson JC. Cervicogenic headache in patients with presumed migraine: missed diagnosis or misdiagnosis? J Pain 2005; 6: 700-3.

4. Antonaci F, Bono G, Chimento P. Diagnosing cervicogenic headache. J Headache Pain 2006; 7: 145-8.

5. Kim SS, Park BS, Lee YJ. The effect of intramuscular stimulation (IMS) in cervicogenic headache. Korean J Anesthesiol 2006; 50: 355-60.
6. Uka K, Aikata H, Takaki S, Shirakawa H, Jeong SC, Yamashina K, et al. Clinical features and prognosis of patients with extrahepatic metastases from hepatocellular carcinoma. World J Gastroenterol 2007; 13: 414-20.

7. Choi HJ, Cho BC, Sohn JH, Shin SJ, Kim SH, Kim JH, et al. Brain metastases from hepatocellular carcinoma: prognostic factors and outcome: brain metastasis from HCC. J Neurooncol 2009; 91: 30713.

8. Natsuizaka M, Omura T, Akaike T, Kuwata Y, Yamazaki K, Sato T, et al. Clinical features of hepatocellular carcinoma with extrahepatic metastases. J Gastroenterol Hepatol 2005; 20: 1781-7.

9. Seinfeld J, Wagner AS, Kleinschmidt-DeMasters BK. Brain metastases from hepatocellular carcinoma in US patients. J Neurooncol 2006; 76: 93-8.

10. Tanabe H, Kondo A, Kinuta Y, Matsuura N, Hasegawa K, Chin M, et al. Unusual presentation of brain metastasis from hepatocellular carcinoma--two case reports. Neurol Med Chir (Tokyo) 1994; 34: 748-53.

11. Narouze SN, Casanova J, Mekhail N. The longitudinal effectiveness of lateral atlantoaxial intra-articular steroid injection in the treatment of cervicogenic headache. Pain Med 2007; 8: 184-8. 